\title{
Systemic Immune-Inflammation Index Has Prognostic Significance In Pancreatic Carcinoma Patients: A Meta-Analysis
}

\author{
Xiaocheng Li \\ The First Affiliated Hospital of Hunan University of Medicine \\ Huapeng Lin \\ Affiliated Hangzhou First People's Hospital \\ Renbin Ouyang \\ The First Affiliated Hospital of Hunan University of Medicine \\ Yaowei Yang \\ University-Town Hospital of Chongqing Medical University \\ Jing Peng ( $\sim$ hyfyy2018@163.com ) \\ The First Affiliated Hospital of Hunan University of Medicine
}

\section{Research}

Keywords: systemic immune-inflammation index, pancreatic carcinoma, prognosis, meta-analysis

Posted Date: December 2nd, 2020

DOI: https://doi.org/10.21203/rs.3.rs-117731/v1

License: (c) (7) This work is licensed under a Creative Commons Attribution 4.0 International License. Read Full License 


\begin{abstract}
Background: Systemic immune-inflammation index (SII) is reportedly a prognostic indicator for several malignancies, including pancreatic carcinoma, although there exists no consensus regarding its significance. In the current study, we used a systematically meta-analysis to evaluate the association between SII and prognosis in pancreatic carcinoma patients.
\end{abstract}

Methods: We screened PubMed, Embase and Cochrane Library databases, through May 2020, and retrieved studies describing the prognostic role of SII in pancreatic carcinoma. We calculated pooled hazard ratio (HR) and $95 \%$ confidence interval (Cl) using a random or fixed effects models to reveal the correlation between SII and prognosis.

Results: A total of 4 studies, comprising 1,749 patients, met our inclusion criteria and were therefore eligible for inclusion. Our meta-analysis showed that elevated SII indicated significantly worse overall survival in patients with pancreatic carcinoma (HR: 1.43, 95\% Cl: 1.24-1.65, P< 0.001), with subgroup analyses, stratified by the TNM stage and treatment, further validating these results. In addition, patients with high SII had poorer cancer-specific survival (HR: 2.32, 95\% Cl: 1.55-3.48, P < 0.001). However, we found no significant associations between SIl with disease-free and relapse-free survival.

Conclusions: These findings indicate that SII is a potential non-invasive and promising tool for predicting clinical outcomes of pancreatic carcinoma patients. However, further studies using adequate designs and larger sample sizes are required to validate our findings.

\title{
Introduction
}

Pancreatic carcinoma is the seventh highest cause of cancer-related mortalities in the world, and one of the most devastating gastrointestinal tumors with a 5year survival rate of only $9 \%[1,2]$. Despite advancements in approaches for early diagnosis and therapy, there has been no significant improvement in survival benefits of pancreatic carcinoma patients, owing to distal metastases or local recurrence [3]. Therefore, it is critical to develop novel and specific prognostic biomarkers for risk stratification in pancreatic carcinoma patients.

Recent studies have demonstrated that inflammatory response is closely associated with tumorigenesis, development and metastasis of various tumors [47]. For example, hematological biomarkers, such as the level of lymphocytes, neutrophils, platelets, neutrophil to lymphocyte ratio (NLR), platelet to lymphocyte ratio (PLR), and C-reactive protein, are now commonly measured and applied in the assessment of systemic inflammatory response [8, 9]. In fact, previous studies have confirmed that parameters are potential prognostic markers in patients with solid tumors [10-13]. Conversely, other research works have reported contradictory results on the prognostic values [14-17]. Numerous studies have also implicated systemic immune-inflammation index (SII), combining platelet, lymphocyte, and neutrophil counts, as a promising inflammation-based biomarker and a prognostic indicator for clinical outcomes in several malignancies, including pancreatic carcinoma [16, 18-20]. Therefore, we sought to comprehensively assess the clinical prognostic effect of SII in pancreatic carcinoma patients using a meta-analysis.

\section{Methods}

\section{Search strategy and study selection}

Two investigators (XC Li and HP Lin) independently performed a systematic online literature search and data extraction. Specifically, electronic scientific databases, including PubMed, Embase and Cochrane Library, were searched and relevant studies identified up to May 2020. The search terms used included "systemic immune-inflammation index", "SII", "pancreatic neoplasms", "pancreatic", and "pancreas", with all searches conducted using a combination of $\mathrm{MeSH}$ terms and free-test words. Furthermore, references of both relevant systematic reviews and included studies were manually reviewed and additional studies identified.

\section{Inclusion and exclusion criteria}

Inclusion criteria include studies that: (1) described the relationship between SIl and prognosis of patients with pancreatic tumors; (2) reported no laboratory or clinical evidence of infection, autoimmune or blood disease; (3) included an optimal cutoff value of SIl; (4) reported outcomes of interest, including cancerspecific survival (CSS), overall survival (OS), disease-free survival(DFS) or relapse-free survival(RFS); (5) in which the hazard ratios (HRs) with $95 \%$ confidence intervals (Cls) of prognostic factors could be extracted or calculated; (6) were written in the English language. On the other hand, exclusion criteria were as follows: (1) studies on cell lines, tissues, or animals; (2) necessary data were not available; (3) continuous variables for SIl; (4) the publication type was case series, review articles, letter, editorial, or commentary.

\section{Data extraction and quality assessment}

All data required for meta-analysis were independently extracted by the aforementioned authors using a prespecified table, and any disagreements resolved through a group discussion to reach a consensus. The collected information included, name of the first author, country of origin, publication year, study period, sample size, study design, baseline characteristics of patients, follow-up time, tumor-node-metastasis (TNM) stage, treatment methods, SIl cut-off value, outcome, HRs and the corresponding $95 \%$ Cls.

We obtained HRs and $95 \%$ Cls for univariate and multivariate analyses in two ways. Firstly, HRs and their corresponding $95 \%$ Cls were directly obtained from the reported literature. Secondly, in cases where the article only provided the Kaplan-Meier curves, HRs and $95 \%$ Cls were calculated from the survival curves using Engauge Digitizer version 4.1 [21]. Methodological quality for each eligible article was independent assessed by the two reviewers using the NewcastleOttawa Scale (NOS). NOS scores of the ranging from 1 to 9 points were considered low to high quality [22], with a score $\geq 6$ denoted high quality. 


\section{Statistical analysis}

Meta-analysis was conducted using the RevMan software, version 5.3 (The Nordic Cochrane Center, Cochrane Collaboration, and Copenhagen, Denmark). Summary statistics were assessed using standard meta-analysis methods, with HRs used as an effect measure to assess the association between SII with prognosis in pancreatic carcinoma patients. Between-study statistical heterogeneity was evaluated using the Higgins 12 statistic and Cochran's Q test, with data followed by $\mathrm{P}<0.10$ and/or $\mathrm{I} 2>50 \%$ considered to have significant heterogeneity. In cases where studies showed a significant homogeneity, a fixedeffect model was adopted, otherwise a random-effect model was applied. Presence of publication bias was determined using the funnel plot, whereas stability and reliability of the results were assessed using sensitivity analysis through the leave-one-out strategy. Data followed by $\mathrm{P}<0.05$ were considered statistically significant.

\section{Results}

\section{Search results and study characteristics}

Our search yielded 43 articles, comprising 23, 13, 3 and 4 studies from EMBASE, PubMed, Cochrane Library, and other sources, respectively. A total of 19 articles remained, following exclusion of duplicates, whereas reviewing abstracts and full text resulted in exclusion of 14 more articles owing to the fact that they were systematic reviews, case reports, comments, and irrelevant studies. We also excluded Zhou et al [11], a recent study considered SII a continuous variable. A summary of the search procedures is illustrated in Fig. 1. Finally, a total of four studies [16, 18-20], involving 1749 patients were included in our analysis. Three of the studies reported OS, whereas the remaining one reported CSS and RFS. One of the studies involved two independent patient cohorts, comprising 197 and 222 patients in the training and validation cohorts, respectively [19]. For this meta-analysis, we treated these two patient cohorts as two studies for further evaluation. The included articles were all retrospective cohort studies and were published between 2018-2020, with a sample size ranging between 321 and 590, and SII cut-off values ranging from 440 to 900 . All included studies had NOS scores $\geq 6$. A detailed description of all included studies is outlined in Table 1.

Table 1

Characteristics of included trials in the review

\begin{tabular}{|c|c|c|c|c|c|c|c|c|c|c|c|c|}
\hline Author & Study design & $\begin{array}{l}\text { Study } \\
\text { period }\end{array}$ & Country/region & $\begin{array}{l}\text { No. of } \\
\text { Sample }\end{array}$ & $\begin{array}{l}\text { Age } \\
\text { (years) }\end{array}$ & Treatment & $\begin{array}{l}\text { Tumor } \\
\text { type }\end{array}$ & $\begin{array}{l}\text { TNM } \\
\text { stage }\end{array}$ & $\begin{array}{l}\text { Median } \\
\text { follow-up } \\
\text { (months) }\end{array}$ & Outcome & $\begin{array}{l}\text { Cut- } \\
\text { off } \\
\text { value }\end{array}$ & $\begin{array}{l}\text { NOS } \\
\text { score }\end{array}$ \\
\hline $\begin{array}{l}\text { Murthy } \\
\text { et al, } \\
2020^{[18]}\end{array}$ & $\begin{array}{l}\text { Retrospective } \\
\text { study }\end{array}$ & $\begin{array}{l}2007- \\
2017\end{array}$ & USA & 419 & $65.17 \pm 9.7$ & Mixed & PDAC & $\triangle-\square$ & $\begin{array}{l}39.1(32.6- \\
48.1)\end{array}$ & OS & 900 & 8 \\
\hline $\begin{array}{l}\text { Jomrich } \\
\text { et al, } \\
2019^{[16]}\end{array}$ & $\begin{array}{l}\text { Retrospective } \\
\text { study }\end{array}$ & $\begin{array}{l}1995- \\
2014\end{array}$ & Austria & 321 & $\begin{array}{l}68.5(35.9- \\
92.3)\end{array}$ & Surgery & PDAC & $\mathbb{Q}-\square$ & 60 & OS, DFS & 873 & 8 \\
\hline $\begin{array}{l}\text { Zhang } \\
\text { et al, } \\
2019^{[19]}\end{array}$ & $\begin{array}{l}\text { Retrospective } \\
\text { study }\end{array}$ & $\begin{array}{l}2011- \\
2015\end{array}$ & China & 419 & $61(25-84)$ & Mixed & PA & $\bigotimes-\square$ & 48 & OS & 440 & 8 \\
\hline $\begin{array}{l}\text { Aziz al, } \\
2018^{[20]}\end{array}$ & $\begin{array}{l}\text { Retrospective } \\
\text { study }\end{array}$ & $\begin{array}{l}2004- \\
2015\end{array}$ & Netherlands & 590 & $\begin{array}{l}65.5(35.5- \\
82.4) / \\
65.6(36.6- \\
84.7)\end{array}$ & Surgery & PDAC & $\triangle-\bigotimes$ & $43.3 / 44.8$ & $\begin{array}{l}\text { CSS, } \\
\text { RFS }\end{array}$ & 900 & 8 \\
\hline
\end{tabular}

Abbreviations: TNM, tumor-node-metastasis; NOS, Newcastle-Ottawa Scale; PDAC, pancreatic ductal adenocarcinoma; PA, pancreatic adenocarcinoma; OS, overall survival; CSS, cancer-specific survival; DFS, disease-free survival; RFS, relapse-free survival

\section{The relationship between SII and OS in pancreatic carcinoma patients}

A total of three cohort studies, comprising 1,159 patients, were combined to evaluate the relationship between SII and OS in pancreatic carcinoma patients. We found no significant heterogeneity among the studies $(I 2=0)$, hence we applied a fixed-effect model. Univariate analysis revealed a pooled HR of 1.44 with the corresponding $95 \% \mathrm{Cl}(1.25-1.65)(\mathrm{P}<0.001)$, whereas multivariate analysis resulted in a $\mathrm{HR}$ of 1.43 with the corresponding $95 \% \mathrm{Cl}(1.24-1.65)(\mathrm{P}<0.001)$. Based on these results, it was evident that higher SII indicated poor OS in pancreatic carcinoma (Fig. 2).

\section{The relationship between SII and CSS/DFS/ RFS in pancreatic carcinoma patients}

Only one study reported the prognostic impact of SII on CSS/DFS/ RFS in pancreatic carcinoma patients. Results indicated that a high SII acts as an independent prognostic marker for CSS (HR: 2.32, 95\% Cl: 1.55-3.48, P<0.001), although no significant differences were recorded between SII and DFS (HR: 1.27, $95 \% \mathrm{Cl}: 0.95-1.70, \mathrm{P}=0.103)$ or RFS (HR: 1.49, 95\% Cl: 1.00-2.20, $\mathrm{P}=0.048)$ in pancreatic carcinoma (Table 2). 


\begin{tabular}{|c|c|c|c|c|c|c|}
\hline \multirow[b]{2}{*}{ Analysis } & \multirow[b]{2}{*}{ No. of studies } & \multirow[b]{2}{*}{ No. of cases } & \multirow[b]{2}{*}{$\mathrm{HR}(95 \% \mathrm{Cl})$} & \multirow[b]{2}{*}{ P-value } & \multicolumn{2}{|c|}{ Heterogeneity } \\
\hline & & & & & $\mathrm{I}^{2}(\%)$ & P-value \\
\hline OS & 3 & 1159 & $1.43(1.24-1.65)$ & $<0.001$ & 0 & 0.97 \\
\hline \multicolumn{7}{|c|}{ TNM stage } \\
\hline $\mathbb{Q} \mathbb{\square}$ & 2 & 740 & $1.39(1.13-1.69)$ & 0.001 & 0 & 0.91 \\
\hline Q- & 1 & 419 & $1.48(1.21-1.80)$ & $<0.001$ & - & - \\
\hline \multicolumn{7}{|c|}{ Treatment } \\
\hline Mixed & 2 & 838 & $1.44(1.22-1.70)$ & $<0.001$ & 0 & 0.90 \\
\hline Surgery & 1 & 321 & $1.40(1.07-1.84)$ & 0.016 & - & - \\
\hline CSS & 1 & 590 & $2.32(1.55-3.48)$ & $<0.001$ & - & - \\
\hline DFS & 1 & 321 & $1.27(0.95-1.70)$ & 0.103 & - & - \\
\hline RFS & 1 & 590 & $1.49(1.00-2.20)$ & 0.048 & - & - \\
\hline
\end{tabular}

\section{Subgroup and sensitivity analyses}

A summary of results from subgroup analyses stratified by the TNM stage and treatment is outlined in Table 2. Summarily, higher SII was a poor prognostic

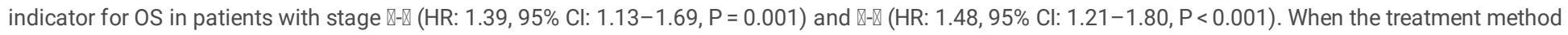
was considered, HRs for the impact of SII on OS were 1.44 (95\% Cl: $1.22-1.70, \mathrm{P}<0.001)$ and 1.40 (95\% Cl: $1.07-1.84, \mathrm{P}=0.016)$ for the mixed and surgery groups, respectively. Moreover, all subgroups revealed significant association between SIl levels and OS of pancreatic carcinoma (Table 2). Subsequent exclusion of a single trial did not alter pooled HRs for the aforementioned associations. Particularly, a comparison among the random and fixed effects models resulted in identical pooled risk estimate of OS. Overall, subgroup and sensitivity analyses indicated that the current pooled evidence from metaanalysis were robust and credible.

\section{Publication bias}

Funnel plots in our meta-analysis revealed no evidence of publication bias among the included studies (Fig. 3).

\section{Discussion}

Numerous studies have suggested that inflammatory response plays a pivotal role in development and progression of tumors [6, 23, 24]. This interaction is reportedly mediated by a series of inflammatory cells, which form major cellular components of the tumor microenvironment [25], and either directly or indirectly affect tumor cell proliferation, migration and angiogenesis by releasing various inflammatory mediators [26, 27]. Other studies have implicated peripheral blood inflammatory cell count, including neutrophils, and lymphocytes in prognosis of many tumors [28-31]. SIl, a combined marker based on platelet, lymphocyte, and neutrophil counts, was first identified as an independent factor for predicting clinical outcomes of hepatocellular carcinoma patients [32]. Thereafter, its prognostic value was revealed in various tumors, including colorectal, renal cell, esophageal squamous cell, lung, prostate, and gastrointestinal cancers [33-38].

SII is a novel and convenient marker, that is easily accessible and inexpensive, and has recently been shown to be a prognostic marker for pancreatic carcinoma. In the present study, literature review-based analysis of the relationship between SIl and prognosis of pancreatic carcinoma patients indicated that patients with higher SII levels have worse prognostic tendency, possibly due to several reasons. Firstly, neutrophils have been proven to promote release of a variety of inflammatory factors, such as vascular epithelial growth factor, neutrophil elastase, interleukin-8, and matrix metalloproteinase-9, which play an important role in promoting the invasion, proliferation, progression, and metastasis of cancer cells, as well as helping these cells to escape immune surveillance [39, 40]. In addition, platelets not only promote adhesion of tumor cells to microvascular endothelium, but also form a defense barrier around circulating tumor cells, helping tumor cells escape the host's immune surveillance [41]. Consequently, they directly promote tumor growth and metastasis by secreting pro-angiogenic factors and platelet-derived growth factors [42]. Conversely, lymphocytes play an important role, defending the body against cancer cells by inducing cell death, inhibiting cell proliferation and migration [5]. Therefore, a reduction in the number of lymphocytes may weaken the antitumor immune response and immune surveillance function, thereby providing a good microenvironment for tumor growth [43, 44]. Based on these mechanisms, presence of high levels of SII, platelets and neutrophils and low levels of lymphocytes, enhances tumor invasion, adhesion, progression, metastasis and weakens antitumor immune response. Thus, an elevated SII is associated with adverse clinical outcomes in tumor patients.

In the present study, we determined SII's prognostic value in pancreatic carcinoma patients, using a total of 4 published studies comprising 1,749 patients. Pooled results indicated that pancreatic cancer patients with high levels of SII had worse OS rates than those with low SII levels. Furthermore, results from subgroup analyses, applied to explore the prognostic significance of SII in patients with different stages and treatment options, suggested that high SII levels were a potential independent poor prognostic marker for OS in patients with resectable or advanced pancreatic tumors. This trend remained, even when 
treatment was considered as a stratification factor, regardless of whether the patient has received surgery or mixed treatment. In addition, we also found that a high SII value was associated with CSS in patients with pancreatic tumors, although these results need further validation.

This study had several limitations. Firstly, the four included articles were retrospective cohort studies, and could have inherent defects. Secondly, the total number of included studies and the sample size was relatively small, especially for some subgroup analyses. Therefore, more large-sample studies are needed to further confirm our findings. Thirdly, we did not make stratified comparisons based on other factors, such as age, gender, and pathological type of tumor owing to the paucity of original data from individual studies. Fourthly, the optimal cut-off value of the SIl was inconsistent across different studies. Finally, although the funnel plots suggested no evidence of publication bias, this may be inevitable because funnel plots lacked adequate statistical power owing to the small number of studies included. Given these several limitations, our study findings should be treated with caution.

In summary, high SII levels are associated with poor prognosis of OS and CSS in pancreatic carcinoma patients. However, SII is no significantly associated with DFS and RFS. The exact biological mechanisms underlying the observed associations are still poorly understood, although previous studies have implicated the inflammatory response pathway in their regulation. Our findings indicate that SII might be a non-invasive and valuable prognostic marker for pancreatic carcinoma for clinical practice. However, well designed, large-scale, and prospective studies are needed to validate the association between SII levels and the prognostic outcomes of pancreatic carcinoma patients.

\section{Abbreviations}

\section{SII}

systemic immune-inflammation index

NLR

neutrophil to lymphocyte ratio

PLR

platelet to lymphocyte ratio

CSS

cancer-specific survival

OS

overall survival

DFS

disease-free survival

RFS

relapse-free survival

HRs

hazard ratios

Cls

confidence intervals

TNM

tumor-node-metastasis

NOS

Newcastle-Ottawa Scale

\section{Declarations}

\section{Ethics approval and consent to participate}

Not applicable

\section{Consent for publication}

Not applicable

\section{Availability of data and materials}

Not applicable

\section{Competing interests}

The authors declare that they have no competing interests.

\section{Funding}

This work was funded by Clinical Medical Technology Demonstration Base for Minimally Invasive Treatment of Hepatobiliary and Pancreatic Diseases in Huaihua.

\section{Acknowledgments}


The authors are grateful to Ms. Shanqiongyao Wang for her consistent support and help during this study. This work was funded by Clinical Medical Technology Demonstration Base for Minimally Invasive Treatment of Hepatobiliary and Pancreatic Diseases in Huaihua.

\section{Author Contributions}

Conception and design: XCL, HPL, JP. Data collection and drafting: XCL, HPL. Statistical analysis: XCL, YWY, RBOY. Manuscript writing: XCL, HPL. Final approval of manuscript: All authors.

\section{References}

1. Bray F, Ferlay J, Soerjomataram I, Siegel RL, Torre LA, Jemal A. Global cancer statistics 2018: GLOBOCAN estimates of incidence and mortality worldwide for 36 cancers in 185 countries. CA Cancer J Clin. 2018;68:394-424.

2. Tsai HJ, Chang JS. Environmental Risk Factors of Pancreatic Cancer. J Clin Med. 2019; 8.

3. Sun X, Liu M, Hao J, Li D, Luo Y, Wang X, et al. Parkin deficiency contributes to pancreatic tumorigenesis by inducing spindle multipolarity and misorientation. Cell Cycle. 2013;12:1133-41.

4. Grivennikov SI, Greten FR, Karin M. Immunity, inflammation, and cancer. Cell. 2010;140:883-99.

5. Padoan A, Plebani M, Basso D. Inflammation and Pancreatic Cancer: Focus on Metabolism, Cytokines, and Immunity. Int J Mol Sci. $2019 ; 20$.

6. Mantovani A, Allavena P, Sica A, Balkwill F. Cancer-related inflammation. Nature. 2008;454:436-44.

7. Shrestha S, Noh JM, Kim S-Y, Ham H-Y, Kim Y-J, Yun Y-J, et al. Angiotensin converting enzyme inhibitors and angiotensin II receptor antagonist attenuate tumor growth via polarization of neutrophils toward an antitumor phenotype. Oncoimmunology. 2015;5:e1067744-e.

8. Takano S, Yoshitomi H, Kagawa S, Furukawa K, Takayashiki T, Kuboki S, et al. Long-term outcomes and significance of preoperative lymphocyte-tomonocyte ratio as a prognostic indicator in patients with invasive pancreatic neoplasms after repeat pancreatectomy. BMC Cancer. 2020;20:111-.

9. Kocarnik JM, Richard M, Graff M, Haessler J, Bien S, Carlson C, et al. Discovery, fine-mapping, and conditional analyses of genetic variants associated with C-reactive protein in multiethnic populations using the Metabochip in the Population Architecture using Genomics and Epidemiology (PAGE) study. Human molecular genetics. 2018;27:2940-53.

10. Hua X, Long Z-Q, Zhang Y-L, Wen W, Guo L, Xia W, et al. Prognostic Value of Preoperative Systemic Immune-Inflammation Index in Breast Cancer: A Propensity Score-Matching Study. Frontiers in oncology. 2020;10:580-.

11. Zhou W, Kuang T, Han X, Chen W, Xu X, Lou W, et al. Prognostic role of lymphocyte-to-monocyte ratio in pancreatic neuroendocrine neoplasms. Endocr Connect. 2020.

12. Lin J-X, Tang Y-H, Wang J-B, Lu J, Chen Q-Y, Cao L-L, et al. Blood parameters score predicts long-term outcomes in stage II-III gastric cancer patients. World journal of gastroenterology. 2019;25:6258-72.

13. Schlick K, Magnes T, Huemer F, Ratzinger L, Weiss L, Pichler M, et al. C-Reactive Protein and Neutrophil/Lymphocytes Ratio: Prognostic Indicator for Doubling overall survival Prediction in Pancreatic Cancer Patients. Journal of clinical medicine. 2019;8:1791.

14. Liu X, Sun X, Liu J, Kong P, Chen S, Zhan Y, et al. Preoperative C-Reactive Protein/Albumin Ratio Predicts Prognosis of Patients after Curative Resection for Gastric Cancer. Transl Oncol. 2015;8:339-45.

15. Hirahara N, Matsubara T, Kawahara D, Nakada S, Ishibashi S, Tajima Y. Prognostic significance of preoperative inflammatory response biomarkers in patients undergoing curative thoracoscopic esophagectomy for esophageal squamous cell carcinoma. Eur J Surg Oncol. 2017;43:493-501.

16. Jomrich G, Gruber ES, Winkler D, Hollenstein M, Gnant M, Sahora K, et al. Systemic Immune-Inflammation Index (SII) Predicts Poor Survival in Pancreatic Cancer Patients Undergoing Resection. J Gastrointest Surg. 2020;24:610-8.

17. Gao XH, Tian L, Wu J, Ma XL, Zhang CY, Zhou Y, et al. Circulating CD14(+) HLA-DR(-/low) myeloid-derived suppressor cells predicted early recurrence of hepatocellular carcinoma after surgery. Hepatol Res. 2017;47:1061-71.

18. Murthy P, Zenati MS, Al Abbas Al, Rieser CJ, Bahary N, Lotze MT, et al. Prognostic Value of the Systemic Immune-Inflammation Index (SII) After Neoadjuvant Therapy for Patients with Resected Pancreatic Cancer. Ann Surg Oncol. 2020;27:898-906.

19. Zhang K, Hua YQ, Wang D, Chen LY, Wu CJ, Chen Z, et al. Systemic immune-inflammation index predicts prognosis of patients with advanced pancreatic cancer. J Transl Med. 2019;17:30.

20. Aziz MH, Sideras K, Aziz NA, Mauff K, Haen R, Roos D, et al. The Systemic-immune-inflammation Index Independently Predicts Survival and Recurrence in Resectable Pancreatic Cancer and its Prognostic Value Depends on Bilirubin Levels: A Retrospective Multicenter Cohort Study. Ann Surg. 2019;270:13946.

21. Goldstein DA, Ahmad BB, Chen Q, Ayer T, Howard DH, Lipscomb J, et al. Cost-Effectiveness Analysis of Regorafenib for Metastatic Colorectal Cancer. J Clin Oncol. 2015;33:3727-32.

22. Li X, Wu YS, Chen D, Lin H. Laparoscopic hepatectomy versus radiofrequency ablation for hepatocellular carcinoma: a systematic review and metaanalysis. Cancer Manag Res. 2019;11:5711-24.

23. Panagopoulos V, Leach DA, Zinonos I, Ponomarev V, Licari G, Liapis V, et al. Inflammatory peroxidases promote breast cancer progression in mice via regulation of the tumour microenvironment. Int J Oncol. 2017;50:1191-200.

24. Shrihari TG. Dual role of inflammatory mediators in cancer. Ecancermedicalscience. 2017;11:721.

25. Qin H, Yu H, Sheng J, Zhang D, Shen N, Liu L, et al. PI3Kgamma Inhibitor Attenuates Immunosuppressive Effect of Poly(I-Glutamic Acid)-Combretastatin A4 Conjugate in Metastatic Breast Cancer. Advanced science (Weinheim, Baden-Wurttemberg, Germany). 2019; 6: 1900327-. 
26. Grinberg-Bleyer Y, Ghosh S. A Novel Link between Inflammation and Cancer. Cancer Cell. 2016;30:829-30.

27. Wislez M, Rabbe N, Marchal J, Milleron B, Crestani B, Mayaud C, et al. Hepatocyte growth factor production by neutrophils infiltrating bronchioloalveolar subtype pulmonary adenocarcinoma: role in tumor progression and death. Cancer Res. 2003;63:1405-12.

28. Sasaki A, Iwashita Y, Shibata K, Matsumoto T, Ohta M, Kitano S. Prognostic value of preoperative peripheral blood monocyte count in patients with hepatocellular carcinoma. Surgery. 2006;139:755-64.

29. Yamagishi T, Fujimoto N, Nishi H, Miyamoto Y, Hara N, Asano M, et al. Prognostic significance of the lymphocyte-to-monocyte ratio in patients with malignant pleural mesothelioma. Lung Cancer. 2015;90:111-7.

30. Kim BW, Jeon YE, Cho H, Nam EJ, Kim SW, Kim S, et al. Pre-treatment diagnosis of endometrial cancer through a combination of CA125 and multiplication of neutrophil and monocyte. J Obstet Gynaecol Res. 2012;38:48-56.

31. Grenader T, Nash S, Plotkin Y, Furuse J, Mizuno N, Okusaka T, et al. Derived neutrophil lymphocyte ratio may predict benefit from cisplatin in the advanced biliary cancer: the ABC-02 and BT-22 studies. Ann Oncol. 2015;26:1910-6.

32. Hu B, Yang XR, Xu Y, Sun YF, Sun C, Guo W, et al. Systemic immune-inflammation index predicts prognosis of patients after curative resection for hepatocellular carcinoma. Clin Cancer Res. 2014;20:6212-22.

33. Passardi A, Scarpi E, Cavanna L, Dall'Agata M, Tassinari D, Leo S, et al. Inflammatory indexes as predictors of prognosis and bevacizumab efficacy in patients with metastatic colorectal cancer. Oncotarget. 2016;7:33210-9.

34. Lolli C, Basso U, Derosa L, Scarpi E, Sava T, Santoni M, et al. Systemic immune-inflammation index predicts the clinical outcome in patients with metastatic renal cell cancer treated with sunitinib. Oncotarget. 2016;7:54564-71.

35. Wang L, Wang C, Wang J, Huang X, Cheng Y. A novel systemic immune-inflammation index predicts survival and quality of life of patients after curative resection for esophageal squamous cell carcinoma. J Cancer Res Clin Oncol. 2017;143:2077-86.

36. Guo D, Zhang J, Jing W, Liu J, Zhu H, Fu L, et al. Prognostic value of systemic immune-inflammation index in patients with advanced non-small-cell lung cancer. Future Oncol. 2018;14:2643-50.

37. Fan L, Wang R, Chi C, Cai W, Zhang Y, Qian H, et al. Systemic immune-inflammation index predicts the combined clinical outcome after sequential therapy with abiraterone and docetaxel for metastatic castration-resistant prostate cancer patients. Prostate. 2018;78:250-6.

38. Zhang Y, Lin S, Yang X, Wang R, Luo L. Prognostic value of pretreatment systemic immune-inflammation index in patients with gastrointestinal cancers. J Cell Physiol. 2019;234:5555-63.

39. Houghton AM, Rzymkiewicz DM, Ji H, Gregory AD, Egea EE, Metz HE, et al. Neutrophil elastase-mediated degradation of IRS-1 accelerates lung tumor growth. Nat Med. 2010;16:219-23.

40. Coffelt SB, Wellenstein MD, de Visser KE. Neutrophils in cancer: neutral no more. Nat Rev Cancer. 2016;16:431-46.

41. Boone BA, Zenati MS, Rieser C, Hamad A, Al-Abbas A, Zureikat AH, et al. Risk of Venous Thromboembolism for Patients with Pancreatic Ductal Adenocarcinoma Undergoing Preoperative Chemotherapy Followed by Surgical Resection. Ann Surg Oncol. 2019;26:1503-11.

42. Meikle CK, Kelly CA, Garg P, Wuescher LM, Ali RA, Worth RG. Cancer and Thrombosis: The Platelet Perspective. Front Cell Dev Biol. $2016 ; 4: 147$.

43. Dunn GP, Old LJ, Schreiber RD. The immunobiology of cancer immunosurveillance and immunoediting. Immunity. 2004;21:137-48.

44. Lianyuan T, Dianrong $X$, Chunhui $Y$, Zhaolai M, Bin J. The predictive value and role of stromal tumor-infiltrating lymphocytes in pancreatic ductal adenocarcinoma (PDAC). Cancer Biol Ther. 2018;19:296-305.

\section{Figures}



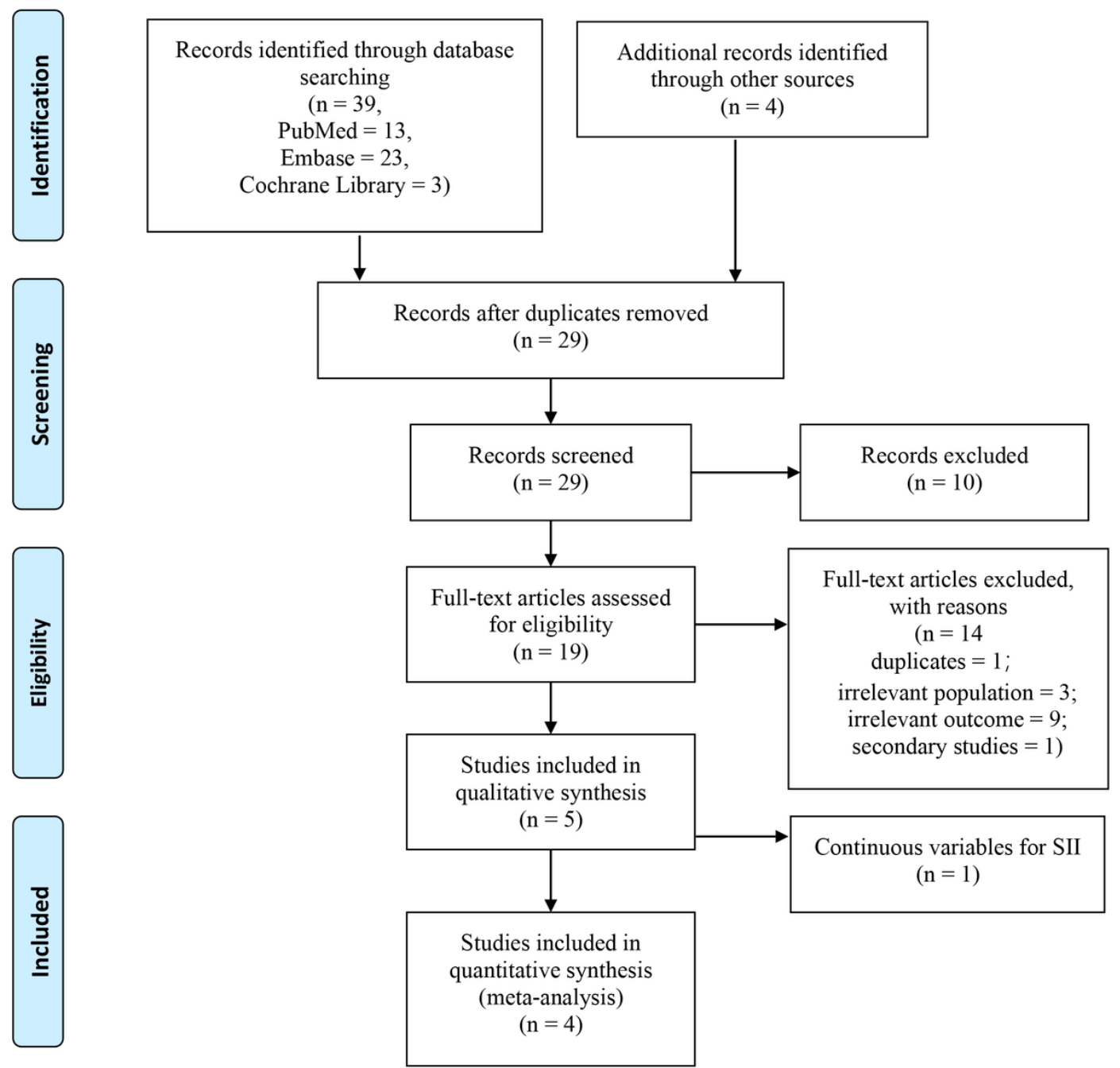

Studies included in quantitative synthesis (meta-analysis) $(n=4)$

Figure 1

Flow chart of study selection 

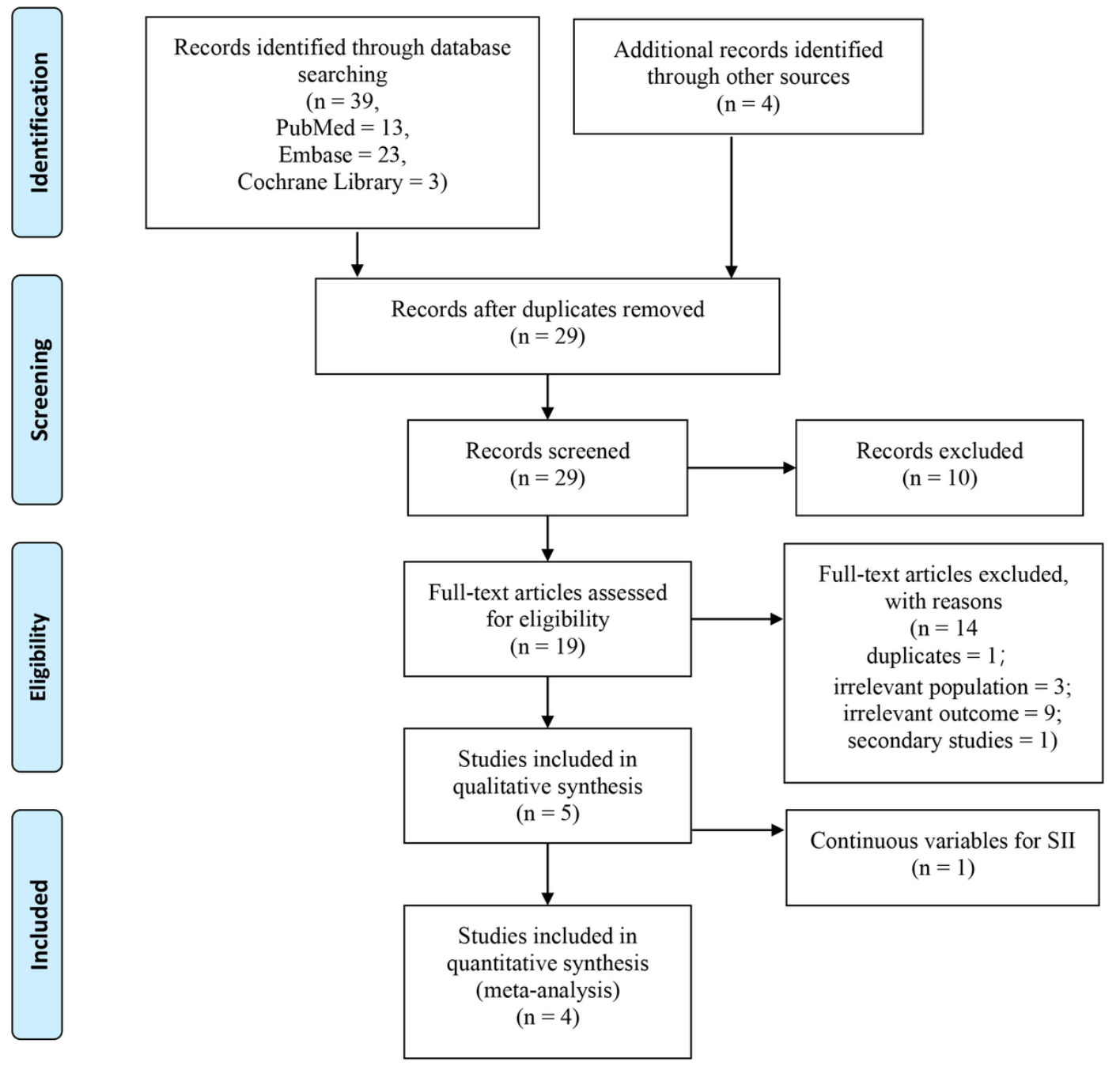

Figure 1

Flow chart of study selection

A

Study or Subgroup

Jomrich 2019

Murthy 2020

Zhang 2019(training)

Zhang 2019(validation)

Total $(95 \% \mathrm{Cl})$

Heterogeneity: $\mathrm{Chi}^{2}=0.62, \mathrm{df}=3(\mathrm{P}=0.89) ; \mathrm{I}^{2}=0 \%$

Test for overall effect: $Z=5.22(P<0.00001)$
Hazard Ratio

log[Hazard Ratio]

$0.3598 \quad 0.128$

$0.2784 \quad 0.1425$

$0.4376 \quad 0.1475$

$\begin{array}{ll}0.3771 & 0.1391\end{array}$

$100.0 \%$
$29.4 \% \quad 1.43[1.12,1.84]$

$23.7 \% \quad 1.32[1.00,1.75]$

$22.1 \% \quad 1.55[1.16,2.07]$

$24.9 \% \quad 1.46[1.11,1.92]$

$1.44[1.25,1.65]$

\section{B}

Study or Subgroup log[Hazard Ratio] Jomrich 2019

Murthy 2020

Zhang 2019(training)

Zhang 2019(validation)

0.33720 .1399

0.31410 .1506

0.40680 .1452

$0.375 \quad 0.1427$

Total $(95 \% \mathrm{Cl})$

$100.0 \%$

Heterogeneity: $\mathrm{Chi}^{2}=0.23, \mathrm{df}=3(\mathrm{P}=0.97) ; \mathrm{I}^{2}=0 \%$

Test for overall effect: $Z=4.97(P<0.00001)$

$$
(n=10)
$$

articles excluded h reasons $(\mathrm{n}=14$

uplicates $=1$;

rrelevant population $=3$; irrelevant outcome $=9$;

condary studies $=1$ )

$$
(\mathrm{n}=1)
$$

\section{Figure 2}


Forest plots describing the association between SII and overall survival. (A) Univariate analysis and (B) multivariate analysis; SII, systemic immuneinflammation index

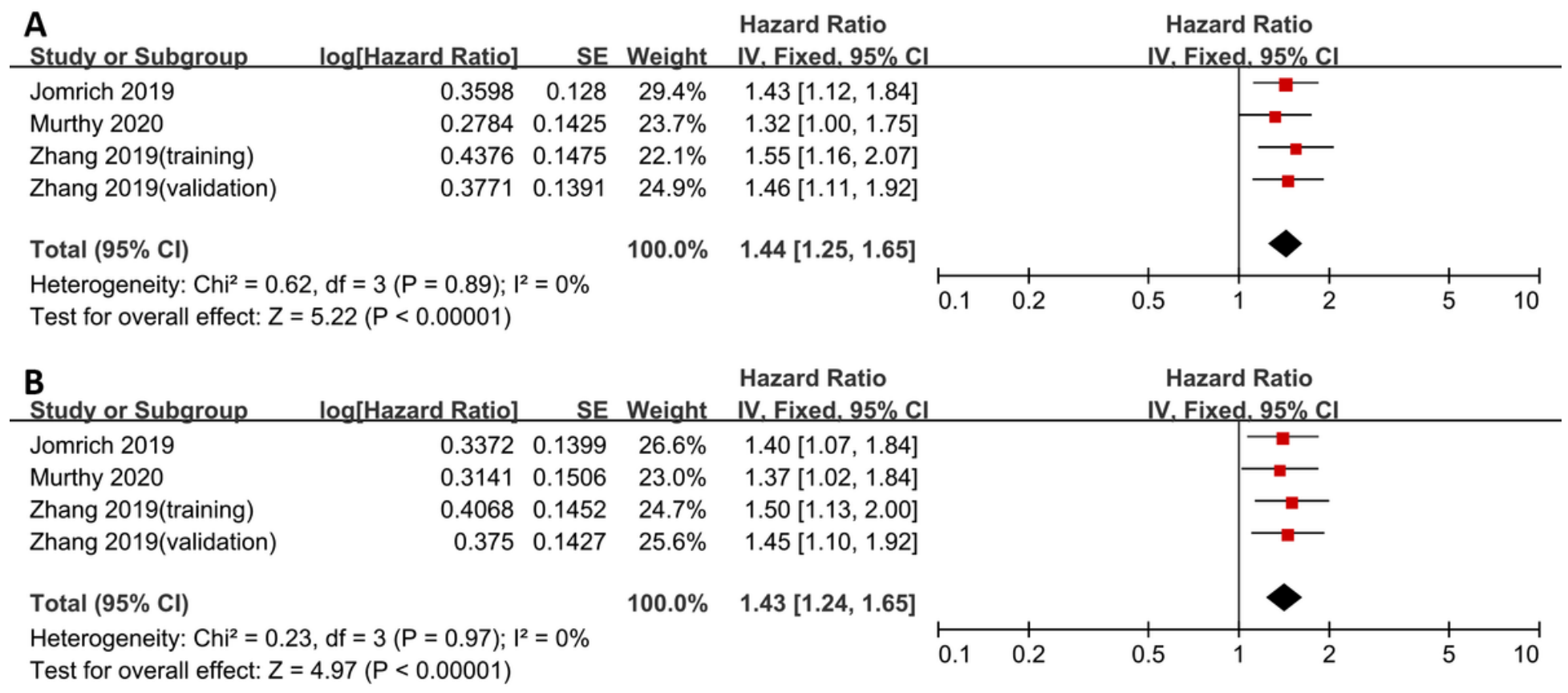

\section{Figure 2}

Forest plots describing the association between SII and overall survival. (A) Univariate analysis and (B) multivariate analysis; SII, systemic immuneinflammation index

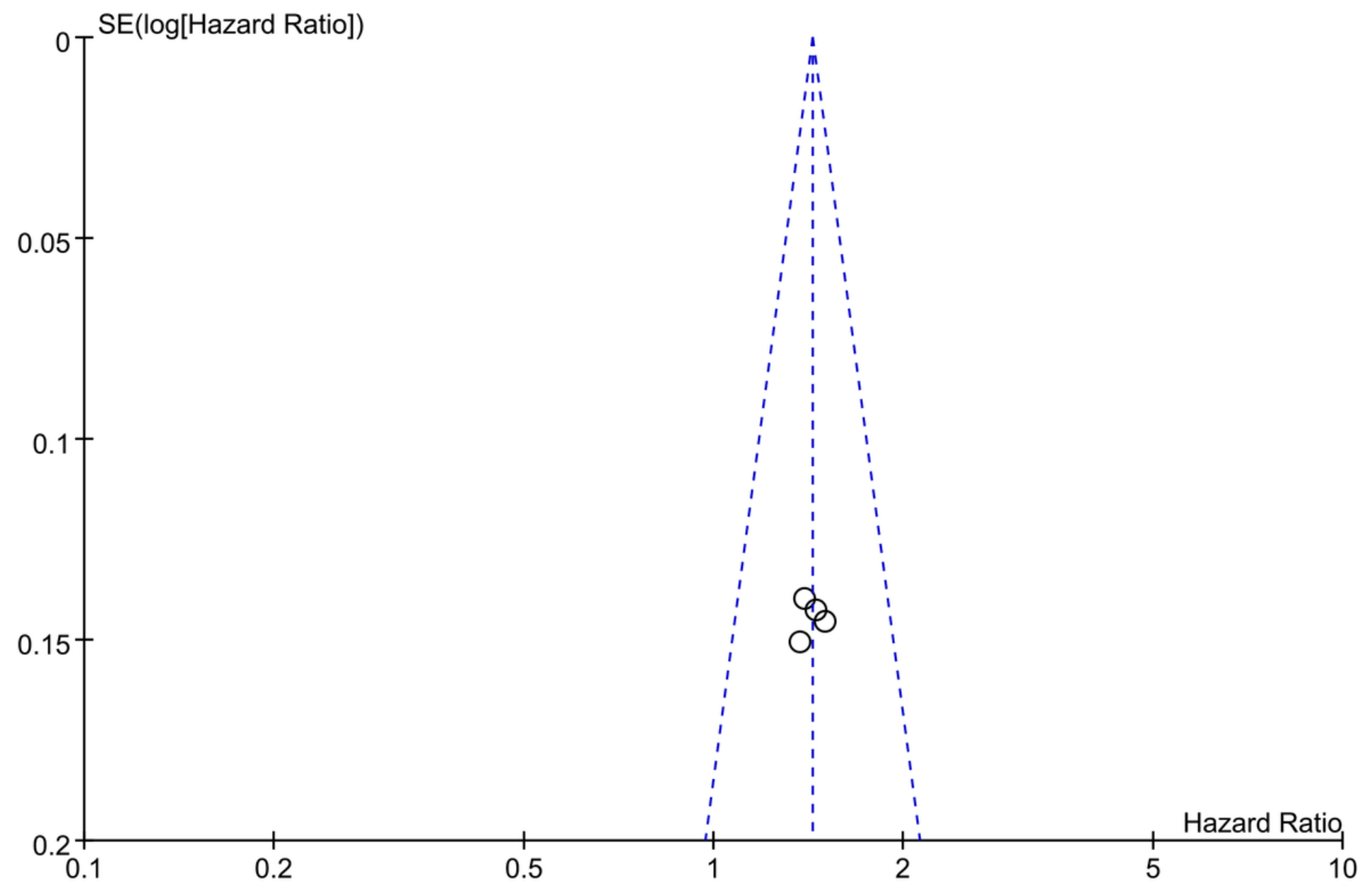


Figure 3

Funnel plots describing the association between SII and overall survival; SII, systemic immune-inflammation index

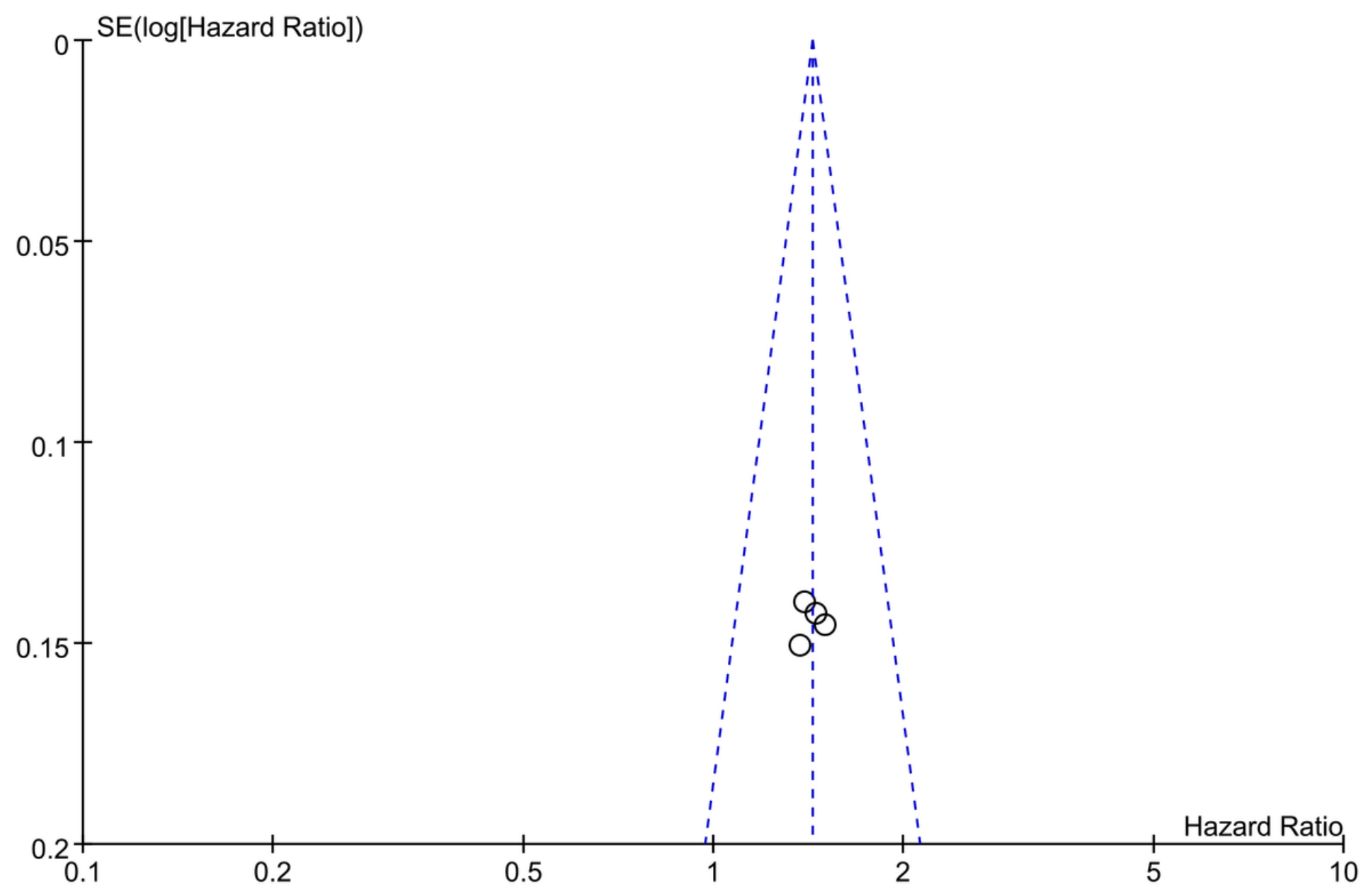

Figure 3

Funnel plots describing the association between SII and overall survival; SII, systemic immune-inflammation index 